\title{
Prediction of littoral drift with Adaptive Neuro-Fuzzy Inference System
}

\author{
MASUMEH SIADATI SABET ${ }^{1}$, MEHDI ABBASZADEH NASERI ${ }^{2}$, \\ HOSEIN SIADATI SABET ${ }^{3}$ \\ ${ }^{1}$ Department of Water Resource Engineering, Bananoor Gil Company, Iran \\ ${ }^{2}$ Department of Electrical Engineering, Karaj Islamic Azad University, Iran \\ ${ }^{3}$ Department of Civil Engineering, Bananoor Gil Company, Iran
}

\begin{abstract}
Prediction of littoral drift with Adaptive Neuro-Fuzzy Inference System. The amount of sand moving parallel to a coastline forms a prerequisite for many harbor design projects. Such information is currently obtained through various empirical formulae. Despite so many works in the past, an accurate and reliable estimation of the rate of sand drift has still remained a problem. It is a non-linear process and can be described by chaotic time-series. The current study addresses this issue through the use of Adaptive Neuro-Fuzzy Inference System (ANFIS). ANFIS is about taking an initial fuzzy inference system (FIS) and tuning it with a back propagation algorithm based on the collection of input-output data. ANFIS was developed to predict the sand drift from a variety of causative variables. The structure and algorithm of ANFIS for predicting the rate of sand drift is described. The Adaptive Neuro-Fuzzy Inference System was validated by confirming its consistency with a database of specified physical process.
\end{abstract}

Key words: littoral sand drift, Adaptive Neuro-Fuzzy Inference System, validation.

\section{INTRODUCTION}

The coastline zone is characterized by a complex interactive system of air, water and land producing a dynamic environment highly sensitive to man-induced changes. Littoral drift indicates movement of sediments parallel to a coastline caused by the breaking action of waves. Ocean waves attacking the shoreline at an angle produce a current parallel to the coast. Such long shore current is responsible for the long shore movement of the sediment [1]. Littoral drift poses severe problems in coastal and harbor operations since it results in siltation of deeper navigation channels due to which ships cannot enter or leave the harbor area. Therefore an accurate estimation of the drift is needed in order to know the amount of excavation required so that corresponding budgetary provisions could be made in advance. Unfortunately, this is easier said than done because the underlying physical process is too complex to model in the form of mathematical equations - either parametric or differential. Despite this, workable empirical formulae that relate the drift to a set of causative variables are currently in use. They are based on collection of measurements made in the field or on a hydraulic model followed by a curve fitting exercise. The technique of fitting normally employed is non-linear statistical regression. Nowadays soft tools like artificial neural networks (ANN) often 
provide better alternative to the statistical methods [2] and hence a variety of investigators have applied the technique of ANN to solve problems in coastal engineering. These works typically include (I) evaluating tidal levels and timings of high and low water [3], (II) predicting sea levels [4], (III) establishing estuarine characteristics [5] and (IV) predicting coastal currents [6]. The application of ANN generally suffers from problems like lack of guarantee of success, arbitrary accuracy, difficult choices related to training schemes, architectures, learning algorithms and control parameters. On the other hand, fuzzy systems have found number of practical applications in identification and prediction. Besides, these systems are thoroughly dealing with ill-defined, uncertain systems, can model the qualitive aspects of human knowledge and reasoning process [7]. Traditionally, to develop a fuzzy system, human experts often carry out the generation of IF-THEN rules by expressing their knowledge. In case of complicated processes it is difficult for human experts to test all the input-output data, to find necessary rules for fuzzy systems. To solve this problem and simplify the generating of IF-THEN rules, several approaches have been applied [8-9]. Nowadays, for this purpose the use of neural networks takes importance. Using neural network structure and its learning abilities the construction of fuzzy system is considered. The integration of fuzzy system and neural network allows constructing computationally efficient hardware and software products. It is connected with the capabilities that they posses. Fuzzy systems provide powerful framework for representation of expert knowledge, neural network provide learning capabilities that increase the flexibility, adaptability of the system. The combination of neural networks with fuzzy knowledge base helps to reduce the searching space and time for achieving optimal solution. The adaptive neuro-fuzzy inference system (ANFIS) structure implements TSK type fuzzy system in a multi layers feed forward neural network structure. Using back-propagation and least square algorithms the learning of neuro-fuzzy system is carried out.

The current study is developed fuzzy inference system based on feed forward neural network to determine the littoral drift. An attempt is made to see how both ANFIS and the statistical regression differ in processing the input information. The consistency of the ANFIS with underlying physical process is further checked.

\section{ANFIS DEVELOPMENT}

\section{Adaptive Neuro-Fuzzy Model}

Neuro-fuzzy is an associative memory system that consists of fuzzy nodes instead of simple input and output nodes, and it uses neural network learning functions to refine each part of the fuzzy knowledge separately. Learning in a separated network is faster than learning in a whole network [10]. An adaptive neuro-fuzzy inference system (ANFIS) is a fuzzy inference system implemented in the framework of an adaptive neural network. By using a hybrid learning procedure, ANFIS can construct an input-output mapping based on both human-knowledge as fuzzy If-Then rules and stipulated input-output data pairs for neural networks training. ANFIS archi- 
tecture is shown in Figure 1(a), where $x$ and $y$ are the inputs, $f$ is the output, $A_{i}$ and $A_{n 2}$ are the input membership functions, $w_{i}$ and $w_{n 2}$ are the rules firing strengths.

ANFIS is an architecture which is functionally equivalent to a Sugeno-type fuzzy rule base. It is a method for tuning an existing rule base with a learning algorithm based on a collection of training data. This allows the rule base to adapt. Training data is used to teach the neurofuzzy system by adapting its parameters (which in essence are fuzzy set membership function parameters) and using a standard neural network algorithm which utilizes a gradient search, so that the mean square output error is minimized. From the ANFIS architecture, shown in Figure 1(a), it is observed that for given values of premise parameters, the overall output can be expressed as a linear combination of the consequent parameters.

ANFIS modeling and prediction starts by obtaining a data set (input-output data points) and dividing it into training and validating data sets. The training data set is used to find the initial premise parameters for the membership functions by equally spacing each of the membership functions. A threshold value for error between the actual and desired output is determined. The consequent parameters are computed using the least squares method. Then, an error for each data pairs is found. If this error is larger than the threshold value, the premise parameters are updated using the back propagation neural networks. This process is terminated when the error becomes less than the threshold value. Then, the testing data points are used to compare the model with actual system for validating purposes. Figure 1(b) shows the ANFIS training and modeling process.

\section{The database used}

The ANFIS was trained with the help of field observations. The location belonged to a four-km stretch of the coast

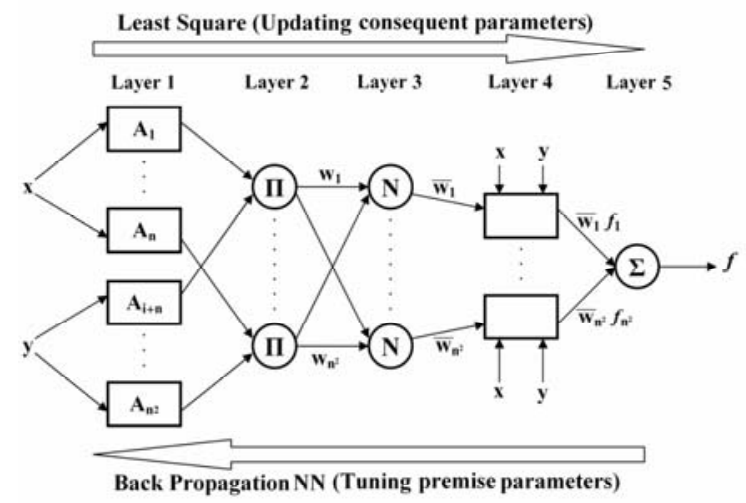

(a)

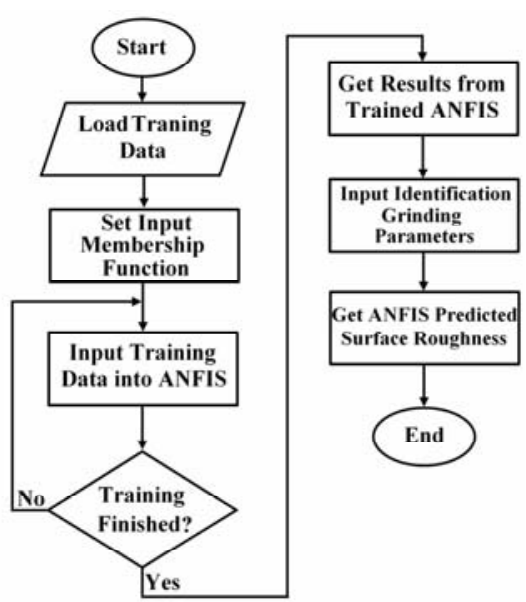

(b)

FIGURE 1. (a) ANFIS Architecture; (b) ANFIS Algorithm 
off Karwar along the western coast of India. These field measurements were done daily from 5 February 1990 to 31 May 1990 by the National Institute of Oceanography at Goa, India [11]. The sediment load was measured along a cross section of the surf zone at six stations at the same time and at a number of points vertically at each station. In each day, the traps were deployed for $6 \mathrm{~h}$ during 07:00 to $13: 00$ and the average sediment load per hour was calculated. Two different traps were used to measure the littoral drift rates. Mesh traps having circular openings were used for measuring the suspended load transport and streamer traps were used for measuring the bed-load transport. The opening of the trap was $0.2 \mathrm{~m}$ wide, $0.15 \mathrm{~m}$ high, and rectangular in shape. The filter cloth mesh opening size was $90 \mu \mathrm{m}$ and the opening of the mesh trap was $0.034 \mathrm{~m}$. The procedure of Kraus [12] was used to determine the total sediment transport and this was based on the trapezoidal rule. The measurements of the significant wave height and average zero cross wave period along with the wave direction corresponding to the spectral peak were made with the help of a WAVEC buoy. The breaking wave height and corresponding angle were derived as per the procedure in [13] and [14] and also visually confirmed. The width of the surf zone was measured daily using a graduated rope. The average longshore currents were measured daily (in terms of the distance covered in two minutes) using the Rhodanine-B type dye injected at the trap locations. A standard sieve analysis gave the median size distribution. When all the parameters such as wave height, wave period, wave direction, longshore current speed and direction and sediment load at different trap locations along the surf zone, were not collected in a day due to malfunctioning of instruments or due to overtopping of traps, then the data of that day were not used in the analysis. The details on the data collection and the estimation of measured sediment load are presented in [15]. The tides were predominantly semi-diurnal with an average spring tide of $2 \mathrm{~m}$ and neap tide of 0.25 $\mathrm{m}$ during the measurement period. The longshore current velocities measured at the trap locations varied from $0.1 \mathrm{~m} / \mathrm{s}$ to $0.6 \mathrm{~m} / \mathrm{s}$ with an average value of $0.3 \mathrm{~m} / \mathrm{s}$.

Table 1 shows ranges of the significant wave height $\left(H_{s}\right)$, average zero cross wave period $\left(T_{z}\right)$, breaking wave height $\left(H_{b}\right)$, breaking angle $\left(\alpha_{b}\right)$, surf zone

TABLE 1. Statistics of the training and testing data set

\begin{tabular}{|c|c|c|c|c|c|c|c|c|c|c|c|c|}
\hline \multirow{2}{*}{$\begin{array}{l}\text { Data } \\
\text { Variable }\end{array}$} & \multicolumn{6}{|c|}{ Training } & \multicolumn{6}{|c|}{ Testing } \\
\hline & $\begin{array}{c}H_{S} \\
{[\mathrm{~m}]}\end{array}$ & $\begin{array}{l}T_{Z} \\
{[\mathrm{~s}]}\end{array}$ & $\begin{array}{c}H_{b} \\
{[\mathrm{~m}]}\end{array}$ & $\begin{array}{c}\alpha_{b} \\
{[\mathrm{deg}]}\end{array}$ & $\begin{array}{c}W \\
{[\mathrm{~m}]}\end{array}$ & $\begin{array}{c}Q \\
{[\mathrm{~kg} / \mathrm{s}]}\end{array}$ & $\begin{array}{c}H_{S} \\
{[\mathrm{~m}]}\end{array}$ & $\begin{array}{l}T_{Z} \\
{[\mathrm{~s}]}\end{array}$ & $\begin{array}{c}H_{b} \\
{[\mathrm{~m}]}\end{array}$ & {$\left[\begin{array}{c}\alpha_{b} \\
{[\mathrm{deg}]}\end{array}\right.$} & $\begin{array}{c}W \\
{[\mathrm{~m}]}\end{array}$ & $\underset{[\mathrm{kg} / \mathrm{s}]}{Q}$ \\
\hline Mean & 0.765 & 5.612 & 0.880 & 5.105 & 40.946 & 15.006 & 0.743 & 5.030 & 0.826 & 4.001 & 41.116 & 15.965 \\
\hline Std. Dev. & 0.256 & 1.512 & 0.200 & 1.850 & 4.488 & 7.774 & 0.224 & 0.889 & 0.214 & 5.934 & 2.913 & 6.547 \\
\hline$\underset{\delta}{\infty}$ Min & 0.336 & 0.528 & 0.511 & 0.965 & 30 & 2.126 & 0.434 & 3.424 & 0.533 & -6.49 & 36.714 & 5.936 \\
\hline$\stackrel{\mathscr{\varpi}}{\simeq} \operatorname{Max}$ & 1.163 & 9.076 & 1.166 & 10.031 & 50 & 31.645 & 1.252 & 7.384 & 1.147 & 9.528 & 47.71 & 25.441 \\
\hline
\end{tabular}




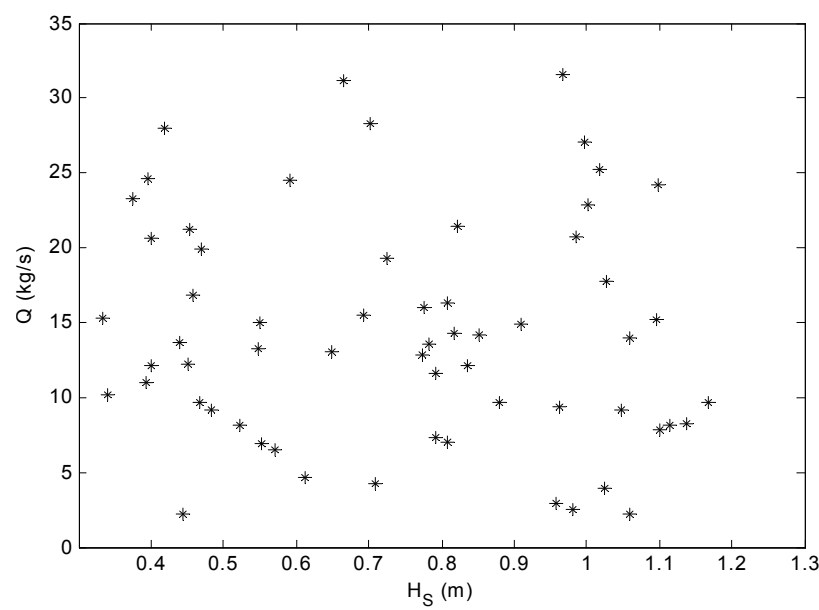

FIGURE 2. Variation of rate of the drift with significant wave height

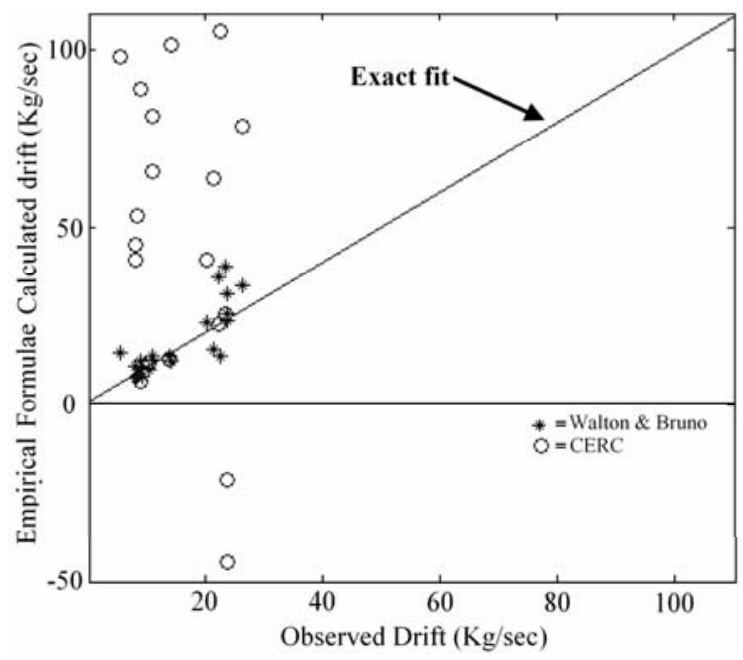

FIGURE 3. Comparison of empirical formulae with observed drift

width $(W)$ as well as rate of the $\operatorname{drift}(Q)$ along with their mean values and standard deviations involved during the training and testing exercises. The rate of littoral drift was found to be randomly varying with the independent causative variables. This is illustrated in the scatter plot of Figure 2.

\section{ANFIS formulation}

The phenomenon of littoral drift is influenced by a variety of causative factorssome of which could be of importance while some others may not be so influential in determining the rate of drift. The Shore Protection Manual [16] as well as 
the Coastal Engineering Manual [17] list the variables above. An ANFIS system with these parameters as input and the rate of drift, $Q$ as output was considered. In total 81 input-output patterns were available through the measured data [11]; out of which 75 percent selected randomly were used for training. Such a trained ANFIS system was tested with the help of remaining 25 percent patterns.

All of the causative variables listed above may not be equally influential in producing the drift at a given location. A sensitivity analysis of the input was done using the pruning method, by [11] in which all causative variables were considered and given as input to a neural network and the network was trained and testing performance in terms of the various error measured thereafter. It is clear that a network that includes the width of the surf zone, $W$, in addition to that of $H_{s}$, $T_{z}, H_{b}$, and $\alpha_{b}$ gives the best accuracy for testing. Hence, in this study, these variables are considered as input to ANFIS system too.

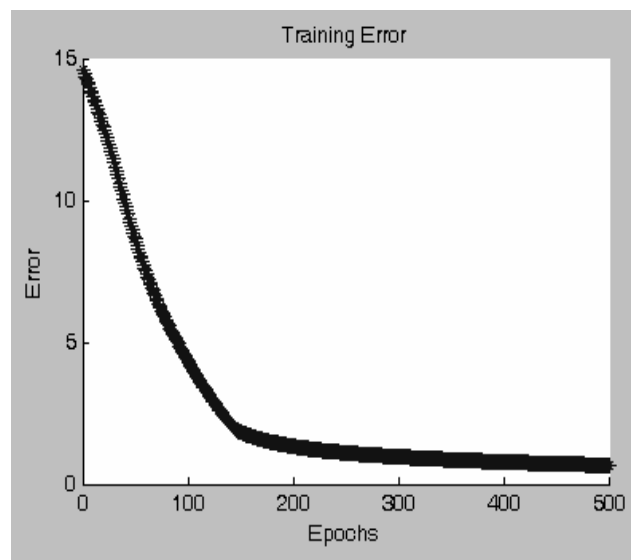

FIGURE 4. ANFIS Training Curve

\section{REGRESSION MODEL}

In order to check how the ANFIS system performs in regard to the statistical regression three new regression equations linear multiple (LM) as well as non-linear $\left(\mathrm{NL}_{1}\right.$ and $\left.\mathrm{NL}_{2}\right)$ were fitted to the training set of data. The resulting equations respectively are [11]:

$$
\begin{aligned}
& Q=-18.7152-13.7319 H_{S}-0.3759 T_{Z}+ \\
& +39.4895 H_{b}-0.3455 \alpha_{b}+0.2340 \mathrm{~W} \\
& Q=0.28 \times H_{S}^{(-0.7693)} \times T_{Z}^{(-0.0704)} \times H_{b}^{(2.7935)} \times \\
& \times \alpha_{b}^{(0.0005)} \times W^{(1.1005)} \\
& \operatorname{Ln} Q=-0.6566-1.2978 H_{S}-0.0264 T_{Z}+ \\
& +3.5802 H_{b}+0.0016 \alpha_{b}+0.0283 \mathrm{~W}
\end{aligned}
$$

\section{ANFIS PREDICTION OF LITTORAL DRIFT}

The ANFIS training for building a neuro-fuzzy model for littoral drift used 61

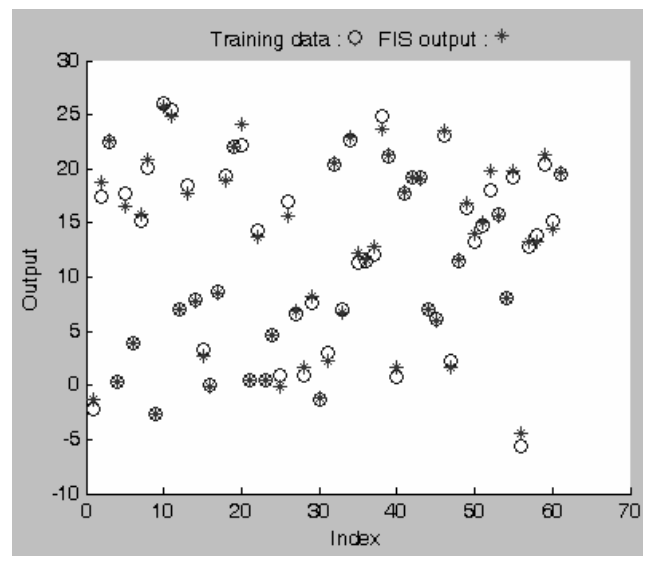

FIGURE 5. Actual and Predicted Littoral Drift Values in Training Mode 


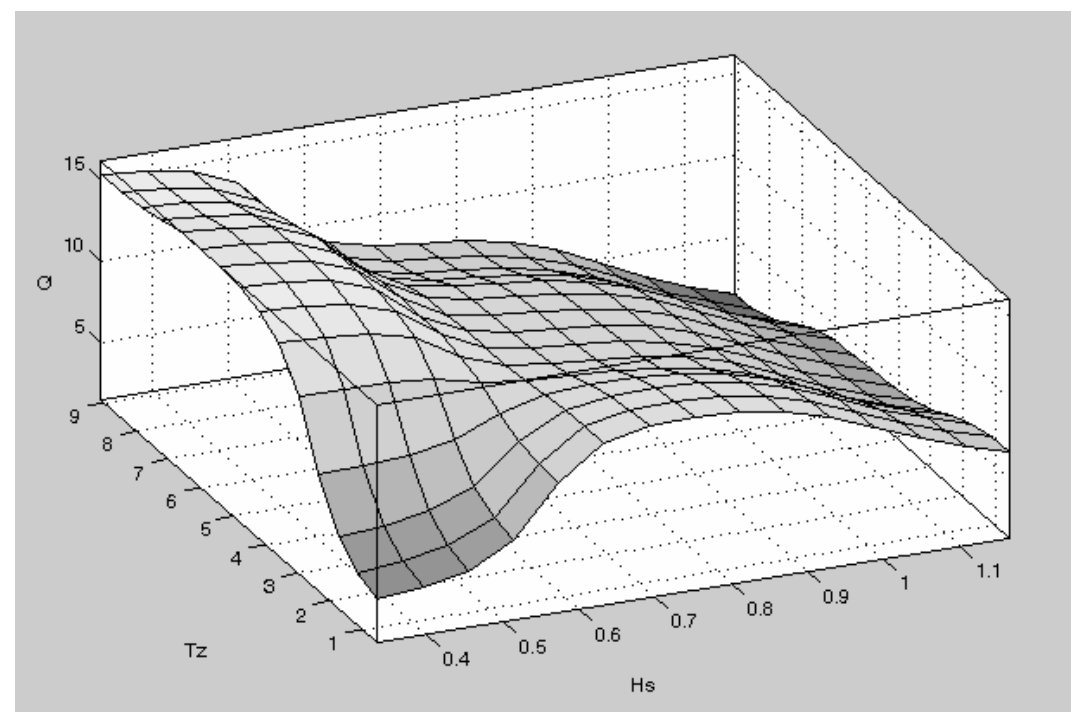

FIGURE 6. Model of Littoral Drift to Significant Height \& Average Zero Cross Wave Period

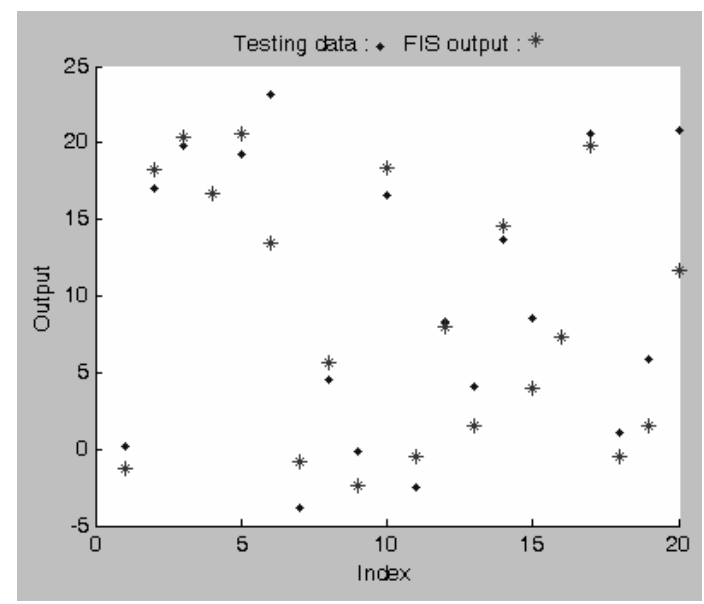

FIGURE 7. Actual and Predicted Littoral Wave Drift Values in Testing Mode

training data points, and 500 learning epochs. Figure 4 shows the training curve of ANFIS with root mean square error (RMSE) of 0.66373 . A comparison between the actual and ANFIS predicted littoral drift values after training is shown in Figure 5, which shows that the system is well-trained to model the actual the rate of littoral drift.

The surface plot of ANFIS-predicted littoral drift as a function of the significant wave height $\left(H_{s}\right)$, average zero cross wave period $\left(T_{z}\right)$, is shown in Figure 6. In Figure 7 a comparison between the 
actual and ANFIS predicted littoral drift values with testing data is shown, which shows that the ANFIS system models the rate of littoral drift truly with root mean square error (RMSE) of 2.5837.

The linear regression and ANFIS prediction models for the rate of littoral drift were validated by feeding into the models the data points that were not used in model's building. Table 2 shows resulting performance over the testing pairs in terms of the root mean square error (RMSE) and mean absolute error (MAE). The last 3 rows of Table 2 show the testing performance of these regression-fits in regard to the ANFIS system, which confirms the necessity of employing ANFIS system for this problem in place of the traditional regression (lower RMSE and MAE). The adequately selected rules (243 rules) thus yielded a higher level of accuracy compared with the traditional regression models; the major underlying reasons being, modelfree estimation procedure and flexibility in the mapping process involved.

TABLE 2. Comparison of the ANFIS and regression result on the testing data set

\begin{tabular}{|l|c|c|}
\hline Scheme & RMSE $[\mathrm{kg} / \mathrm{s}]$ & MAE $[\mathrm{kg} / \mathrm{s}]$ \\
\hline ANFIS & 2.584 & 2.218 \\
LM & 5.356 & 4.773 \\
NL $_{1}$ & 5.271 & 3.935 \\
NL $_{2}$ & 5.615 & 4.019 \\
\hline
\end{tabular}

Different types of membership functions (MF) of the inputs and output were tested to train the ANFIS prediction system. A three generalized bell curve MF for the significant wave height $\left(H_{s}\right)$, two generalized bell curve MF for average zero cross wave period $\left(T_{z}\right)$, three generalized bell curve MF for breaking wave height $\left(H_{b}\right)$, three generalized bell curve MF for breaking angle $\left(\alpha_{b}\right)$ and two generalized bell curve MF for surf zone width $(W)$, resulted in high accurate modeling results and minimum training and validation errors. The final (MF) were tuned and updated by the ANFIS model to achieve a good mapping of the input variables to the rate of littoral drift output. In General, as given in Table 2, the neuro-fuzzy technique achieved better results with a lower average value of RMSE than the linear regression technique.

\section{CONCLUSION}

The Adaptive Neuro-Fuzzy Inference System was developed to predict the rate of littoral drift from a variety of causative variables. The statistical regression methods and an adaptive neuro-fuzzy inference system are used to model and predict the littoral drift of the coast off Karwar along the western coast of India for the period 5 February 1990 to 31 May 1990. An analysis showing how both ANFIS and statistical regression process the input is also presented. It is found that the regression performs rigid approximations with changing input compared with the ANFIS and due to this its accuracy drops. The developed neuro-fuzzy was found to be consistent with the underlying physical process and generally followed expected trends in the variables of the drift with an increase in the values of causative parameters.

The littoral drift values predicted by statistical regression and by ANFIS models are compared to the actual measured values in order to determine the error of both prediction techniques and validate the results. 


\section{REFERENCES}

[1] KOMAR P.D., 1976: "Beach processes and sedimentation, Englewood Cliffs", Prentice Hall.

[2] ASCE Task Committee, 2000: "The ASCE task committee on application of artificial neural networks in hydrology", Hydrology Eng. J., 5(2), pp 115-136.

[3] DEO M.C., CHAUDHARI G., 1998: "Tide prediction using neural networks", Journal of Computer-Aided Civil and Infrastructural Engineering, Blackwell Publishers, Oxford, UK, 13(1998), pp 113-120.

[4] VAZIRI M., 1997: "Predicting Caspian Sea Surface Water Level by ANN and ARIMA models", ASCE Journal of Waterways, 123(4), pp 158-162.

[5] GRUBERT J.P., 1995: "Prediction of estuarine instabilities with artificial neural networks", ASCE J. Comput. Civil Eng., 9(4), pp 226-274.

[6] BABOVIC V., KANIZARES R., JENSON H.R., KLINTING A., 2001: "Neural networks as routine for error updating of numerical models", J. Hydraul. Eng. ASCE, 127(3), pp 181-193.

[7] ZADEH L.A., 1975: "The concept of linguistic variable and its application to approximate reasoning", Information Sciences, v. 8.

[8] YAGER R.R., ZADEH L.A., 1994: "Fuzzy sets, neural networks and soft computing", New York, Van Nostrand Reinhold.

[9] PEDRYZW., 1996: "FuzzyModelling: Paradigms and Practice", Kluwer Academic Publisher, Boston.

[10] JANG J., 1993: ANFIS: adaptive-networkbased fuzzy inference system, IEEE transactions on systems, Man and Cybernetics, Vol. 23, pp 665-685.

[11] SINGH A.K., DEO M.C., SANIL KUMAR V., 2008: Prediction of littoral drift with artificial neural networks, Hydrol. Earth Syst. Sci., 12, pp 267-275.

[12] KRAUS N.C., 1987: Application of portable traps for obtaining point measurements of sediment transport rates in the surf zone, J. Coastal Res., 3(2), pp 139-152.
[13] SKOVGAARD O., JONSSON I.G., BERTELSEN J.A., 1975: Computation of wave heights due to refraction and diffraction, Journal of Waterways, Harbor and Coastal Engineering ASCE, 101(1), pp 15-32.

[14] WEISHAR L.L., BYRNE R.J., 1978: Field study of breaking wave characteristics. Proceedings of 16th Coastal Engineering Conference, American Society of Civil Engineers, New York, pp 487-506.

[15] KUMAR V.S., ANAND N.M., CHANDRAMOHAN P., NAIK G.N., 2003: Longshore sediment transport rate-measurement and estimation, central west coast of India, Coastal Eng., 48, pp 95-109.

[16] Department of the Army, Corps of Engineers, 1984: Shore Protection Manual, US Army Coastal Engineering Research Centre, U.S. Govt., Washington DC.

[17] Department of the Army, Corps of Engineers, 2002: Coastal Engineering Manual, US Army Coastal Engineering Research Centre, U.S. Govt., Washington DC.

Streszczenie: Ocena dryfu morskiego z wykorzystaniem systemu ANFIS (Adaptive Neuro-Fuzzy Inference System). W artykule przedstawiono adaptację systemu ANFIS do oceny wielkości dryfu fal piaskowych poruszających się wzdłuż wybrzeża morskiego. Pomimo wielu informacji o charakterze ilościowym oraz jakościowym zebranych w badaniach terenowych oraz opracowanych wzorów empirycznych opisujących analizowane zjawisko, autorzy widzą potrzebę stosowania symulacji zjawiska za pomocą metod numerycznych. Takie możliwości daje omówiony w pracy system ANFIS.

\section{MS. received April 2010}

\section{Author's address:}

\section{Mehdi Abbaszadeh Naseri}

ICS co. Shahinvila - Ghalam - Sahebzaman No 20 3193837748 Karaj Iran

Islamic Republic of Iran e-mail: abbaszadeh.n@gmail.com 